\title{
Towards Minimizing Underwater Noise from Ships
}

\author{
Seung-Jae Lee* \\ Seoul National University, Republic of Korea
}

Submission: September 18, 2017; Published: October 04, 2017

*Corresponding author: Seung-Jae Lee, Research Institute of Marine Systems Engineering, Seoul National University, Republic of Korea; Tel: 82-10-3308-3515; Email: hul94@snu.ac.kr

\section{Review}

Underwater noise from commercial ships has historically been less of a concern until recently when its negative effect on the marine environment has become much obvious [1]. The eyeopening international event happened in 1996. The Alliance, an oceanographic research vessel operated by the North Atlantic Treaty Organization (NATO), was conducting experiments with the new sonar off the coast of Greece. Several hours after the experiments, 17 beaked whales stranded in the Kyparissiakos Gulf and subsequently died [2]. In the middle of the ongoing debate over SURTASS (Surveillance Towed Array Sensor System), the unusual mass stranding of cetaceans was discovered in the Bahamas islands in the spring of 2000 [3]. Similar accidents such as these triggered a considerable concern on the detrimental impact of man-made underwater noise on marine life, such as marine mammals and fish (for a short review on anthropogenic underwater noise, see [4]).

In 2004 and 2007, the US National Oceanographic and Atmospheric Administration (NOAA) held an international conference to discuss underwater noise from ships. The NOAA addressed that underwater noise has been doubling every 10 years and such an increase has been dominated by ships, particularly in the Northern Hemisphere where $80 \%$ of ship traffic occurs [2,5]. Green Marine, which was launched in 2007 by major marine industry associations, announced shippingnoise evaluation criteria to mitigate underwater noise pollution. In 2014, the International Maritime Organization (IMO) issued guidelines on reducing underwater noise from commercial ships. Although the Green Marine program and the IMO guidelines in reducing shipping noise are currently no legal enforcement, they have been raising awareness of underwater noise in shipping industry, oil and gas industry, ship design and building industry, and others.

Underwater noise from a ship is caused by propellers and hull vibrations. Vibration from machinery is transferred into the surrounding structure, causing underwater noise to radiate from a hull. Since machinery is isolated to sufficiently reduce its vibration before reaching the hull, a relatively small amount of underwater noise can arise from onboard machinery. However, underwater noise caused by machinery might become dominant once propeller cavitation does not occur [6]. There exist two kinds of propeller-induced underwater noise; cavitation and singing noise. Propeller singing is caused by the resonance of the blades excited due to a vortex shedding mechanism at the trailing edge. The undesirable propeller singing typically has a single frequency between 100 and $1,000 \mathrm{~Hz}$ [7]. The faster rotating and small propeller, the higher the singing frequency will be [8]. Since the propeller singing causes stress crack or structural failure of the blade, however, it should be prevented by anti-singing treatments such as an asymmetric trailingedge (for more information, refer to [9]). The most crucial source of underwater noise from a ship is cavitation, which is known to peak at $50-150 \mathrm{~Hz}$ (at blade passing frequency and its harmonics) can be broadband up to $10 \mathrm{kHz}$ [10]. Source level from large commercial ships is typically in 180-195dB re $1 \mu \mathrm{Pa}$ and dominate ambient underwater noise in many marine environments $[11,12]$. The slower speed of ships can yield noncavitation conditions, thus notably decreasing underwater noise levels. From a practical perspective, however, simply slowing down may not be so straightforward. Underwater noise from ships operated by thrusters is effective enough to increase ambient underwater noise in some areas. Although they make less underwater noise relative to propeller-driven ships, a key problem is that most of their operational time spends in coastal and offshore areas which overlap in space with marine animals. Also, ice-breaking ships are a source of underwater noise in polar regions. They produce more variable underwater noise than other vessels because of their operations such as backingand-ramming into the ice. They have a source level of 190 $200 \mathrm{~dB}$ re $1 \mu \mathrm{Pa}[13,14]$. A bubbler system to prevent ice pieces from jamming into the sides of an ice breaker is an additional contributor to underwater noise levels [15].

Voluntary guidelines as a preliminary step toward regulations began to take into consideration underwater noise emission of an individual ship. In response, ship building companies would need to make more effort to design quieter 
propellers at various operating conditions. The existing technology, such as propeller boss cap fins (PBCF), Kort nozzles, Kappel propellers, and air injection to propeller, is effective enough to reduce propeller cavitation noise emitted into the marine environment. Unfortunately, however, underwater noise reductions are often not free. Solutions to have an appropriate balance between acoustical effectiveness and economic viability must be implemented on a case-by-case basis.

\section{References}

1. Spence JH, Fischer RW (2017) Requirements for reducing underwater noise from ships. IEEE Journal of Oceanic Engineering 42(2): 388-398.

2. McCarthy E (2004) International Regulation of Underwater Sound, Kluwer Academic Publishers, Netherlands.

3. Evans DL, England GR (2001) Bahamas marine mammal stranding; event of 15-16 March 2000. Joint Interim Report, U.S. Department of Commerce and U.S. Secretary of the Navy.

4. Hildebrand JA (2009) Anthropogenic and natural sources of ambient noise in the ocean. Marine Ecology Progress Series 395: 4-20.

5. Southall BL, Scholik-SA (2008) Potential application of vessel-quieting technology on large commercial vessels. Final report of the NOAA International Conference, 1-2 May, 2007, Silver Spring, Maryland, USA

6. Lee SJ, Kim HJ, Lee JH, Kim JH, Seo J S (2010) Prediction of underwater noise for environmental impacts: Evaluation of a commercial vessel and offshore structure. 2010 SNAME Annual Meeting, Bellevue, Washington, USA.
7. Richardson WJ, Greene CR, Malme CI, Thomson DH (1995) Marine Mammals and Noise, Academic Press, San Diego, California, USA.

8. Carlton J (2007) Marine propellers and propulsion ( $2^{\text {nd }}$ edn), Butterworth-Heinemann, Burlington, Massachusetts, USA.

9. Fischer R (2008) Singing propellers - solutions and case histories. Marine Technology 45(4): 221-227.

10. Ross D (1976) Mechanics of underwater noise. Pergamon Press, New York, USA

11. Götz, T, Hastie G, Hatch LT, Raustein O, OSPAR Commission (2009] Overview of the impacts of anthropogenic underwater sound in the marine environment. London, UK, England.

12. Veirs S, Veirs V, Wood JD (2016) Ship noise extends to frequencies used for echolocation by endangered killer whales. Peer J doi:10.7717/ peerj.1657.

13. Cosens SE, Dueck LP (1993) Icebreaker noise in Lancaster Sound, N.W.T., Canada: Implications for marine mammal behavior. Marine Mammal Science 9(3): 285-300.

14. Roth EH, Schmidt V, Hildebrand JA, Wiggins SM (2013) Underwater radiated noise levels of a research icebreaker in the central Arctic Ocean. J Acoust Soc Am 133(4): 1971-1980.

15. Erbe C, Farmer DM (2000) Zones of impact around icebreakers affecting Beluga whales in the Beaufort Sea. J Acoust Soc Am 108 (3 Pt 1): $1332-1340$

\section{Your next submission with Juniper Publishers will reach you the below assets}

